\title{
Epidemiology, Clinical Features, and Outcomes of Coccidioidomycosis, Utah, 2006-2015
}

\author{
Adrienne Carey, Morgan E. Gorris, Tom Chiller, Brendan Jackson, Wei Beadles, Brandon J. Webb
}

On the basis of a 1957 geographic Coccidioides seropositivity survey, 3 counties in southwestern Utah, USA, were considered coccidioidomycosis-endemic, but there has been a paucity of information on the disease burden in Utah since. We report findings from a recent clinical and epidemiologic study of coccidioidomycosis in Utah. To describe clinical characteristics, we identified all coccidioidomycosis cases in an integrated health system in the state during 2006-2015. For epidemiologic analysis, we used cases reported to the Utah Department of Health during 2009-2015. Mean state incidence was 1.83 cases/100,000 population/year. Washington County, in southwestern Utah, had the highest incidence, 17.2 cases/100,000 population/year. In a generalized linear model with time as a fixed effect, mean annual temperature, population, and new construction were associated with regional variations in incidence. Using these variables in a spatiotemporal model, we estimated the adjusted regional variation by county to predict areas where Coccidioides infections might increase.

C occidioidomycosis, also known as Valley fever, is caused by Coccidioides immitis and C. posadasii, endemic, dimorphic environmental fungi found in the soil of the southwestern United States, Mexico, and Central and South America (1). Clinical infection ranges from asymptomatic to diverse manifestations including pneumonia, soft tissue and osteoarticular infection, meningitis, and disseminated disease (2). On the basis of findings from the seminal 1957 seropositivity survey (3) that established the com-

Author affiliations: University of Utah School of Medicine, Salt Lake City, Utah, USA (A. Carey); Los Alamos National Laboratory, Los Alamos, New Mexico, USA (M. Gorris); Centers for Disease Control and Prevention, Atlanta, Georgia, USA (T. Chiller,

B. Jackson); Utah Department of Health, Salt Lake City

(W. Beadles); Intermountain Healthcare, Salt Lake City

(B. Webb); Stanford University School of Medicine, Palo Alto,

California, USA (B. Webb)

DOI: https://doi.org/10.3201/eid2709.210751 monly accepted geographic distribution of Coccidioides in the United States, 6 states were classified as coccidioidomycosis-endemic (Arizona, California, Nevada, New Mexico, Texas, and Utah); California and Arizona had the highest seroprevalence (4). On the basis of that study, 3 counties in southwestern Utah were considered coccidioidomycosis-endemic: Iron, Kane, and Washington (3). With the exception of reports from a widely publicized 2001 outbreak of coccidioidomycosis at an archeological dig in Uintah County in the US Park Service's Dinosaur National Monument (5-7), there are few published data on this disease in Utah. However, recent data suggest that southwestern Utah might represent an area of increased disease burden (8). Here we report a description of the epidemiology of coccidioidomycosis in Utah and explore environmental and climatic factors contributing to regional variations in statewide incidence using data from cases reported to the Utah Department of Health (UDOH) during 2009-2015. We also describe clinical characteristics and outcomes using patient-level data from the Intermountain Healthcare System during 2006-2015.

\section{Methods}

\section{Clinical Characteristics}

To describe the clinical characteristics and outcomes of coccidioidomycosis, we used patient-level data from Intermountain Healthcare, an integrated health network with 21 hospitals and 180 clinics in urban and rural Utah. Each year, 1.5 million unique patients, over half of Utah's 2010 population of 2,763,885 (https://www.census.gov/quickfacts/UT), receive care in the Intermountain Healthcare network. We identified all cases of proven or probable coccidioidomycosis recorded during January 1, 2006-December 31,2015 , by applying a previously published query methodology to clinical data from the Intermountain electronic data warehouse. We used an iterative 
search process by querying each of 7 different types of clinical and diagnostic data associated with the diagnosis of coccidioidomycosis: codes from the International Classification of Diseases (ICD) 9th (code range 114.x) and 10th (code range B38.x) Revisions, laboratory tests for Coccidioides, microbiologic culture data, pathologic data, radiologic data, pharmacy data for antifungal medications, and composite data identifying immunocompromised patients at higher risk for fungal disease (9). Laboratory data included serologic assays for Coccidioides: IgM/IgG by ELISA, IgM/IgG by immunodiffusion, complement fixation (CF) titers for IgG (ARUP Laboratories, https:/ / www.aruplab. com), and PCR for Coccidioides (Mayo Medical Laboratories, https:/ / www.mayocliniclabs.com).

We extracted demographic and other clinical data for patients in the Intermountain electronic data warehouse cohort, then manually reviewed all potential cases identified by electronic query to verify the diagnosis by laboratory, microbiologic, and pathologic test results; we validated correlating clinical symptoms using imaging reports, clinical notes, and electronic medical record (EMR) data. We classified each case as proven or probable according to definitions established by the European Organization for Research and Treatment of Cancer/Invasive Fungal Infections Cooperative Group and Mycoses Study Group (EORTC/ MSG) (10). We considered cases proven if they met $\geq 1$ of the following requirements: histopathologic, cytopathologic, or direct microscopic evidence of Coccidioides spherules with tissue damage from sterile specimen or tissue biopsy; culture from any specimen or tissue biopsy positive for C. immitis or C. posadasii; positive blood culture for C. immitis or C. posadasii; positive Coccidioides serology in cerebrospinal fluid; or 2-dilution rise in Coccidioides CF titer measured in consecutive blood samples tested concurrently. We considered cases probable if case-patients had a Coccidioides CF titer $>1: 2$ or positive IgM or IgG by enzyme immunoassay (EIA)/ELISA or immunodiffusion in the setting of a compatible clinical syndrome, which could include $\geq 1$ of the following: 1) systemic infection with fever, chills, night sweats, weight loss; 2) cutaneous or musculoskeletal infection; 3) pulmonary involvement with nodules, cavitation, hilar lymphadenopathy; 4) meningitis; or 5) visceral infiltration. We included case data in the study if the cases met criteria for proven or probable infection (Figure 1).

For the Intermountain Healthcare cohort used for describing clinical characteristics, we included cases from small communities just outside the Utah border for which Intermountain Healthcare facilities serve as the primary access to healthcare. These cases were not included in the cohort used for epidemiologic analyses. We excluded cases in which it was clear from the EMR that the infection was acquired outside of Utah and surrounding communities. We also excluded cases that did not meet the EORTC/MSG definition for proven or probable infection. Because of the higher likelihood of a false positive test with ELISA IgM, we excluded cases if the ELISA IgM was positive but not the ELISA IgG and a diagnosis other than coccidioidomycosis was considered more likely. We also excluded cases with a positive ELISA IgG alone and no corresponding clinical signs or symptoms. We manually confirmed the location of diagnosis and management using the patient's residential ZIP code from EMRs. If the city of residence was identified but not the ZIP code, we randomly imputed 1 of the ZIP codes corresponding to that city. We reviewed clinical notes for information regarding disease presentation, reasons for testing for coccidioidomycosis, and interpretation of laboratory results by the physician. We also documented whether antifungal drugs were prescribed and the duration of treatment.

\section{Epidemiologic Analyses}

For epidemiologic analyses, we used data from UDOH to ensure we evaluated the entire state population. For this cohort, we included case counts by county by year during 2009-2015. We excluded cases from before 2009 because of acknowledged limitations in data accuracy before that time. As a sensitivity analysis, we compared agreement between results from the case-finding methodology applied to the Intermountain Healthcare data with records from $\mathrm{UDOH}$ of cases diagnosed within Intermountain Healthcare facilities.

\section{Statistical Analysis}

Descriptive statistics to compare clinical characteristics were performed using a $\chi^{2}$ test for categorical data and the Mann-Whitney U-test for nonnormally distributed continuous data. To compare characteristics between patients with pulmonary and nonpulmonary disease, we developed a logistic regression model including factors significant at an a-significance of $<0.1$, then reduced it to a parsimonious model. We confirmed the goodness of fit using the HosmerLemeshow method and fitted a simple least-squares linear regression to model the variation in statewide incidence over time.

To explore the association between environmental and anthropological features and geographic variation in observed coccidioidomycosis incidence, we developed a generalized linear model using year, 
annual population for 2006-2015 (US Census Bureau, https://www.census.gov), PRISM AN81m mean annual air temperature and precipitation (https:// prism.oregonstate.edu) (11,12), and total annual new construction permits per 100,000 population for 2006-2015 (Ivory-Boyer Construction Report and Database, https://gardner.utah.edu/economics/ ivory-boyer-construction-database) as covariates. We included year to account for potential fixed-year effects and population to capture differences in signals and levels of cases between urban versus rural counties. We included temperature and precipitation data because both climate factors have been shown to correlate with cases in other endemic regions $(8,13-16)$. Last, we included new construction permits because coccidioidomycosis outbreaks have occurred in areas with construction activity, caused by soil-disrupting activities that increase airborne dust containing Coccidioides spp. (17-19). We also explored the contributions of soil $\mathrm{pH}$ (SSURGO database, https:// www.nrcs.usda.gov/wps/portal/nrcs/detail/soils/ survey/?cid=nrcs142p2_053627) and soil frost-free days and freeze-free intervals (Utah Climate Center, https://climate.usu.edu) but ultimately did not include these in the final model. We assessed model fitness using F-test, $\mathrm{R}^{2}$, and residuals. Then, to predict geographic variation in coccidioidomycosis incidence after accounting for environmental and construction factors and the secular trend, we used an analysis of covariance model using county as a fixed variable to estimate the adjusted mean incidence. We input these estimated adjusted incidences into a spatiotemporal geographic information systems model to map predicted incidence by county for the time period. Statistical analysis was conducted using SPSS Statistics 22 (IBM, https://www.ibm.com). This study was approved by the Intermountain Healthcare institutional review board.

\section{Results}

\section{Demographic and Clinical Data}

From the 788 cases we electronically identified initially, 364 patients had serologic, microbiological, or pathological evidence of proven or probable coccidioidomycosis (Figure 1); we excluded an additional 115 patients living in the endemic regions of Utah because they had positive IgG results from ELISA but no evidence of clinical disease. We classified 192 $(52.7 \%)$ of the 364 cases as proven and $172(47.3 \%)$ as probable (Table 1). Median age of case-patients was 61 years (range 1-97 years); $3.6 \%$ were $<18$ years of age. Over half $(55.2 \%)$ of patients were male, and $87.9 \%$

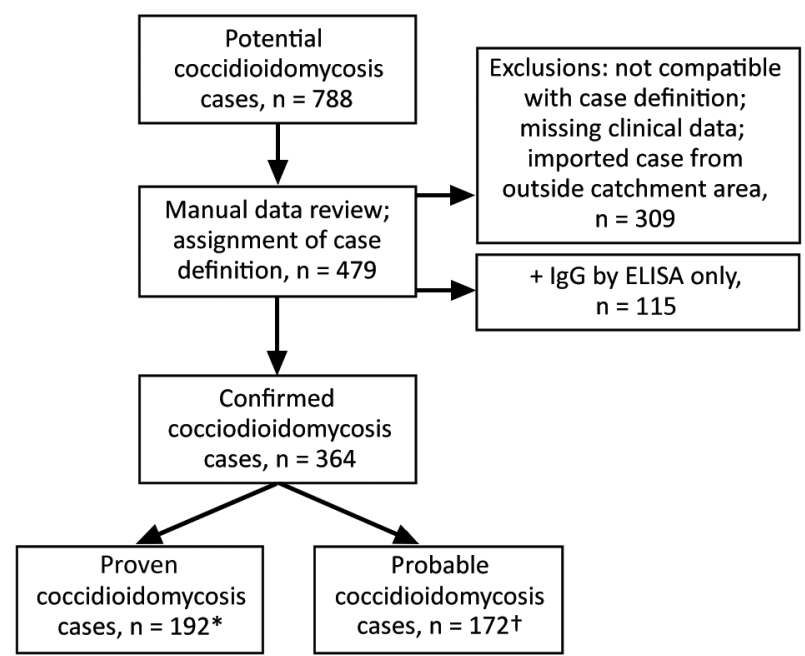

Figure 1. Flowchart showing process for inclusion of possible coccidioidomycosis studies in study of cases in Utah, 2006-2015. Confirmed cases had $\geq 1$ of the following: 1) histopathological, cytopathological, or direct microscopic evidence of Coccidioides spherules with tissue damage from sterile specimen or tissue biopsy; 2) culture from any specimen or tissue biopsy positive for C. immitis or C. posadasii; 3 ) blood culture positive for $C$. immitis or $C$. posadasii; 4) positive Coccidioides serology in cerebrospinal fluid; or 5) two-dilution rise in Coccidioides CF titer measured in consecutive blood samples tested concurrently. Probable cases had a Coccidioides complement fixation titer $>1: 2$ or positive IgM or IgG by EIA/ ELISA or immunodiffusion in the setting of a compatible clinical syndrome and $\geq 1$ of the following: 1) systemic infection with fever, chills, night sweats, weight loss; 2) cutaneous or musculoskeletal infection; 3) pulmonary involvement with nodules, cavitation, hilar lymphadenopathy; 4) meningitis; or 5) visceral infiltration. Definitions based on criteria set by the European Organization for Research and Treatment of Cancer/ Invasive Fungal Infections Cooperative Group; National Institute of Allergy and Infectious Diseases Mycoses Study Group (10).

identified as white. Patients had a median Charlson comorbidity score of 2 (range $0-4$ ); the most common coexisting conditions were chronic pulmonary disease $(144,39.6 \%)$, diabetes mellitus $(81,22.3 \%)$, and malignancy $(76,20.9 \%)$. Only a few patients were taking immunosuppressive medications (27, 7.4\%) or undergoing chemotherapy $(4,1.1 \%)$ at the time of their diagnosis, and 154 (42.3\%) patients were hospitalized for coccidioidomycosis with the length of stay $0-5$ days ( 0 indicating only an emergency room visit); $25.3 \%$ of the cohort had $\geq 1$ hospitalization within $\leq 6$ weeks after diagnosis. All-cause mortality was 5.5\% at 42 days and $9.1 \%$ at 1 year.

\section{Sites of Infection}

Primary pulmonary infection was the most common type of infection, in $323(88.7 \%)$ of 364 patients; $4(1.1 \%)$ pulmonary patients had meningitis. Of 41 
Table 1. Demographic and clinical data from coccidioidomycosis cases identified in the Intermountain Healthcare system, Utah, USA, 2006-2015*

\begin{tabular}{|c|c|}
\hline Variables & No. (\%) \\
\hline Total patients & 364 \\
\hline \multicolumn{2}{|l|}{ Demographics } \\
\hline Age, y, median (IQR) & $61(44-72)$ \\
\hline Pediatric $<18$ y & $13(3.6)$ \\
\hline Male sex & $201(55.2)$ \\
\hline \multicolumn{2}{|l|}{ Race } \\
\hline American Indian & $5(1.4)$ \\
\hline Asian & $2(0.5)$ \\
\hline Black & $1(0.3)$ \\
\hline Hispanic & $20(5.5)$ \\
\hline Pacific Islander & $9(2.5)$ \\
\hline Unknown & $7(1.9)$ \\
\hline White & $320(87.9)$ \\
\hline \multicolumn{2}{|l|}{ Coexisting conditions/medical factors } \\
\hline Charlson comorbidity score, median (IQR) & $2(0-4)$ \\
\hline Diabetes mellitus & $81(22.3)$ \\
\hline Hepatic disease & $61(16.8)$ \\
\hline Chronic pulmonary disease & $144(39.6)$ \\
\hline Connective tissue disease & $27(7.4)$ \\
\hline Congestive heart failure & $53(14.6)$ \\
\hline Neurologic disease & $52(14.3)$ \\
\hline Renal disease & $45(12.4)$ \\
\hline History of malignancy & $76(20.9)$ \\
\hline Hematopoietic stem cell transplant & $2(0.5)$ \\
\hline Solid organ transplant & $2(0.5)$ \\
\hline Any immunosuppressive medication & $27(7.4)$ \\
\hline Corticosteroids & $25(6.9)$ \\
\hline Anti-TNF & $3(0.8)$ \\
\hline Antimetabolite & $2(0.5)$ \\
\hline Chemotherapy & $4(1.1)$ \\
\hline \multicolumn{2}{|l|}{ Laboratory test results } \\
\hline Lymphopenia, absolute lymphocyte count $<500$ & $12(3.3)$ \\
\hline Lymphopenia value at diagnosis, absolute lymphocyte count, median (IQR) & $300(300-400)$ \\
\hline \multicolumn{2}{|l|}{ Outcomes } \\
\hline Coccidioidomycosis-related hospital admission & $154(42.3)$ \\
\hline Hospital length of stay, $d$, median (IQR) & $0(0-5)$ \\
\hline 42-d all-cause mortality & $20(5.5)$ \\
\hline 1-y all-cause mortality & $33(9.1)$ \\
\hline \multicolumn{2}{|l|}{ Case classification } \\
\hline Proven & $192(52.7)$ \\
\hline Probable & $172(47.3)$ \\
\hline
\end{tabular}

patients with nonpulmonary disease, $11(26.8 \%)$ had disseminated infection (Table 2; Appendix Table 1, https://wwwnc.cdc.gov/EID/article/27/9/210751-App1.pdf). We noted no significant differences in age or coexisting conditions, but did find a trend toward significance $(p \leq 0.05)$ for chronic neurologic disease, diagnosed in $24.4 \%(10 / 41)$ of nonpulmonary disease patients compared with 13.0\% (42/323; $\mathrm{p}=0.08$ ) of pulmonary disease patients (Appendix Table 1). Among all those with nonpulmonary disease, $22.2 \%(9 / 41)$ were nonwhite patients, but only $10.8 \%(35 / 323 ; p=0.05)$ of patients with pulmonary disease were nonwhite. Nonpulmonary disease was also more common than pulmonary disease in patients receiving immunosuppressive medications, $14.6 \%(6 / 41)$ versus $6.5 \%(21 / 323 ; p=0.06)$ and those with lymphopenia preceding diagnosis, $9.8 \%(4 / 41)$ versus $2.5 \%(8 / 323 ; p=0.04)$. In a multivariable logistic regression including use of any immunosuppressing medication, neurologic disease, and lymphopenia, only lymphopenia remained a predictor for nonpulmonary disease (OR 4.56, 95\% CI 1.2-14.8).

\section{Diagnosis and Management}

We confirmed a coccidioidomycosis diagnosis with serologic testing in $51.9 \%$ of cases and with microbiologic or pathologic evidence of Coccidioides in $48.1 \%$ of cases (Table 2). Patients were diagnosed in a hospital in $110(30.2 \%)$ cases; among outpatients, $23.1 \%$ were diagnosed by a pulmonologist, $11.8 \%$ by a primary care provider, $10.7 \%$ by a surgeon, and only $0.8 \%$ by an infectious disease physician. Of interest, 104 patients $(28.6 \%)$ were diagnosed as part of a workup for malignancy, usually for an incidental pulmonary 
nodule. Of the 364 patients in the study, 209 (57.4\%) were treated with antifungal therapy alone; $12.6 \%$ of case-patients received no surgical or antifungal therapy (Appendix Table 2). Fluconazole (91.7\%) was the most common antifungal agent prescribed, followed by amphotericin B (3.2\%); $20.8 \%$ of patients received $>1$ different antifungal agent during their treatment.

\section{Epidemiology and Geographic Variation}

We found 366 cases reported during 2009-2015. Mean observed statewide incidence was 1.83 cases/100,000 population/year; yearly rates increased by a mean of 0.02 cases/100,000 population/year from 2009 through $2015\left(R^{2}=0.018\right.$, Figure 2). Washington County, in the southwestern part of the state, accounted for the largest proportion (47.5\%) of cases, a mean observed incidence of 17.2 cases / 100,000 population/ year (Figure 3, Table 3). Outside of Washington County, incidence was next highest in the adjacent southwestern counties of Beaver, Garfield, Iron, and Kane, then in Daggett and Rich Counties in the northeast corner of the state (Table 3; Figure 3). In the generalized linear model accounting for temporal trend, the factors that best explained regional variation in observed incidence included population (effect size [partial $\left.\eta^{2}\right] 0.068, p=0.001$ ), mean air temperature (effect size $0.246 ; \mathrm{p}<0.001$ ), and new construction permits/
100,000 population (effect size $0.072 ; \mathrm{p}=0.001$ ), but precipitation was not significantly associated (effect 0.022; $p=0.059 ; R^{2}=0.42$ ) (Appendix Table 3).

For the analysis of covariance model, in which we used county as a fixed effect and adjusted by secular trend, population, mean annual temperature, precipitation, and new construction permits, the estimated mean statewide incidence was 3.45 cases $/ 100,000$ population/year $\left(\mathrm{R}^{2}=0.92\right)$; (Table 3; Appendix Table 4). In this model, estimated adjusted mean incidence was highest in Washington County at 17.2 cases/100,000 population per year. The estimated incidence was higher than the observed incidence in Summit, Uintah, Duchesne, Morgan, and Rich Counties in northeastern Utah (Table 3).

\section{Discussion}

These data, representing the results of a modern epidemiologic study, confirm coccidioidomycosis as a clinically relevant endemic mycosis in Utah. Our analyses benefited from the granularity of patientlevel data combined with UDOH statewide data. Although not on the scale of incidence reported for Arizona (154.6 cases/100,000 population/year) or California (9.37 cases/100,000 population/year) (20-22), the incidence (1.83 cases/100,000 population/year) in Utah during 2009-2015 was higher than

\begin{tabular}{|c|c|c|c|}
\hline \multirow[b]{2}{*}{ Characteristic } & \multicolumn{3}{|c|}{ No. (\%) cases } \\
\hline & Total & Proven & Probable \\
\hline Total & $364(100)$ & $192(52.7)$ & $172(47.3)$ \\
\hline \multicolumn{4}{|l|}{ Primary method of diagnosis } \\
\hline Laboratory & $189(51.9)$ & $17(8.9)$ & $172(100)$ \\
\hline Microbiology & $43(11.8)$ & $43(22.4)$ & 0 \\
\hline Pathology & $106(29.1)$ & $106(55.2)$ & 0 \\
\hline Microbiology, pathology & $26(7.1)$ & $26(13.5)$ & 0 \\
\hline \multicolumn{4}{|l|}{ Infection site } \\
\hline Abdomen, peritoneal fluid & $1(0.3)$ & $1(0.5)$ & 0 \\
\hline Adrenal & $2(0.5)$ & $2(1.0)$ & 0 \\
\hline Back & $1(0.3)$ & $1(0.5)$ & 0 \\
\hline Disseminated & $11(3.0)$ & $10(5.2)$ & $1(0.6)$ \\
\hline Extremity & $6(1.6)$ & $6(3.1)$ & 0 \\
\hline Liver & $1(0.3)$ & 0 & $1(0.6)$ \\
\hline Lung only & $316(86.8)$ & $154(80.2)$ & $162(94.2)$ \\
\hline Lung and lymph node & $7(1.9)$ & $7(3.6)$ & 0 \\
\hline Lymph node only & $4(1.1)$ & $4(2.1)$ & 0 \\
\hline Meningitis & $4(1.1)$ & $3(1.6)$ & $1(0.6)$ \\
\hline Skin & $5(1.4)$ & $3(1.6)$ & $2(1.2)$ \\
\hline Unknown & $6(1.6)$ & $1(0.5)$ & $5(2.9)$ \\
\hline \multicolumn{4}{|l|}{ Location of diagnosis } \\
\hline Urgent care/emergency department & $12(3.3)$ & $2(1.0)$ & $10(5.8)$ \\
\hline Inpatient hospital & $110(30.2)$ & $59(30.7)$ & $51(29.7)$ \\
\hline Primary care provider & $43(11.8)$ & $22(11.5)$ & $21(12.2)$ \\
\hline Pulmonary department & $84(23.1)$ & $40(20.8)$ & $44(25.6)$ \\
\hline Infectious diseases & $3(0.8)$ & 0 & $3(1.7)$ \\
\hline Surgery department & $39(10.7)$ & $38(19.8)$ & $1(0.6)$ \\
\hline Other & $24(6.6)$ & $19(9.9)$ & $5(2.9)$ \\
\hline Unknown & $50(13.7)$ & $12(6.3)$ & $38(22.1)$ \\
\hline Diagnosed as work-up for malignancy & $104(28.6)$ & $100(52.1)$ & $4(2.33)$ \\
\hline
\end{tabular}




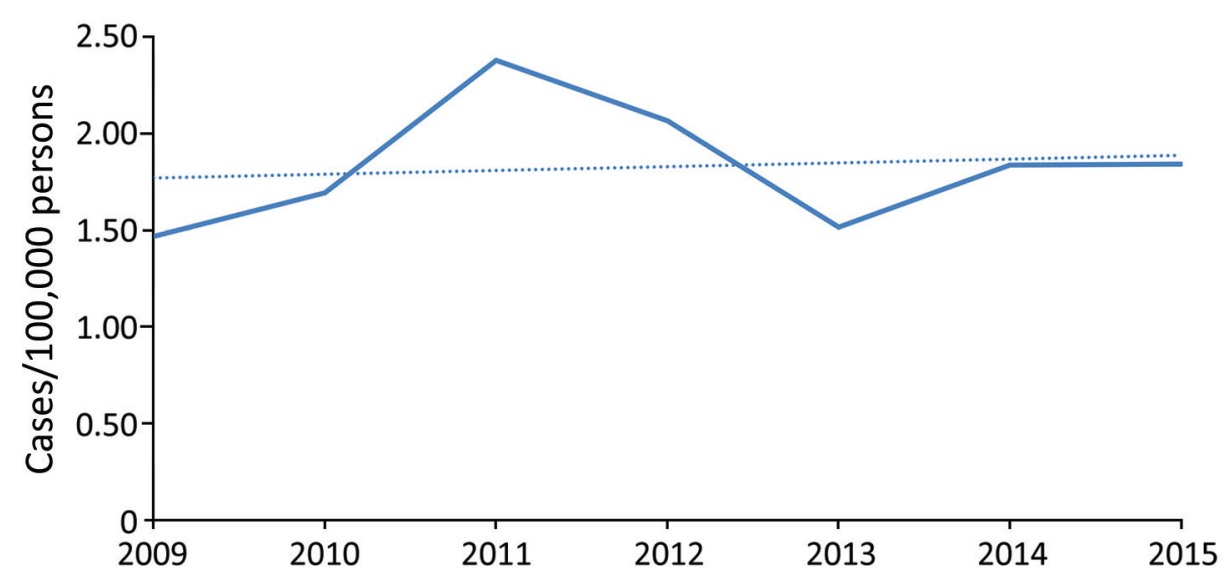

Figure 2. Annual statewide coccidioidomycosis incidence calculated from cases reported to the Utah Department of Health, Utah, 2009-2015. The dotted line represents the line of best fit for the data with an $\mathrm{R}^{2}$ of 0.018 . previously reported, and Utah ranks as the third most endemic state (4).

Coccidioidomycosis clusters regionally within the state. Washington, Garfield, Beaver, Kane, and Iron Counties in the southwestern portion of the state account for the most cases. Although regional climate contributes to this distribution, rapid population growth and new construction in this area of the state might also play a role. As of 2018, St. George, located in Washington County, was one of the fastest growing metropolitan areas in the United States (US Census Bureau). Residential and commercial construction disrupts soil and exposes residents to aerosolized arthroconidia, increasing the risk for contracting coccidioidomycosis $(19,23)$. With increasing population growth in this area, we hypothesize that the rate of coccidioidomycosis incidence will also continue to rise. Future studies focusing on incidence among construction workers or residents living in areas with increased rates of construction will be key to further understand this association. Washington County also represents a large recreational area for travelers, both those commuting to other destinations in the Interstate 15 corridor and those traveling to Zion National Park, the fourthmost visited national park in the United States in
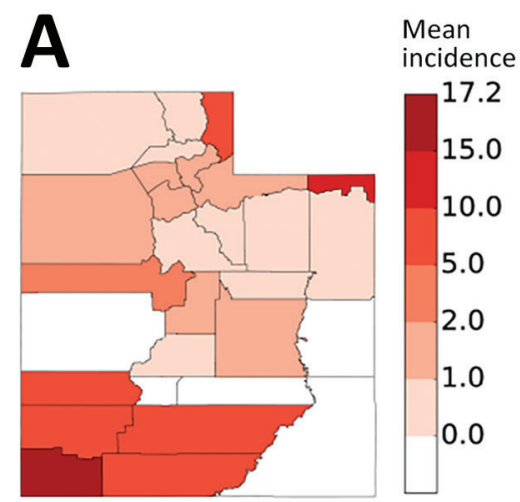

D

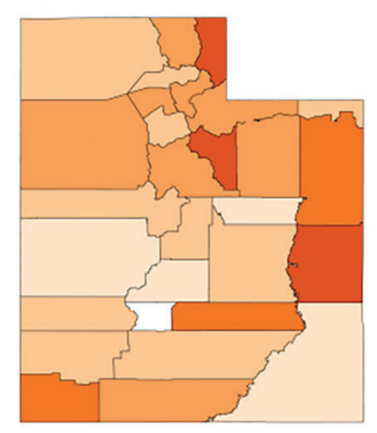

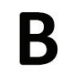
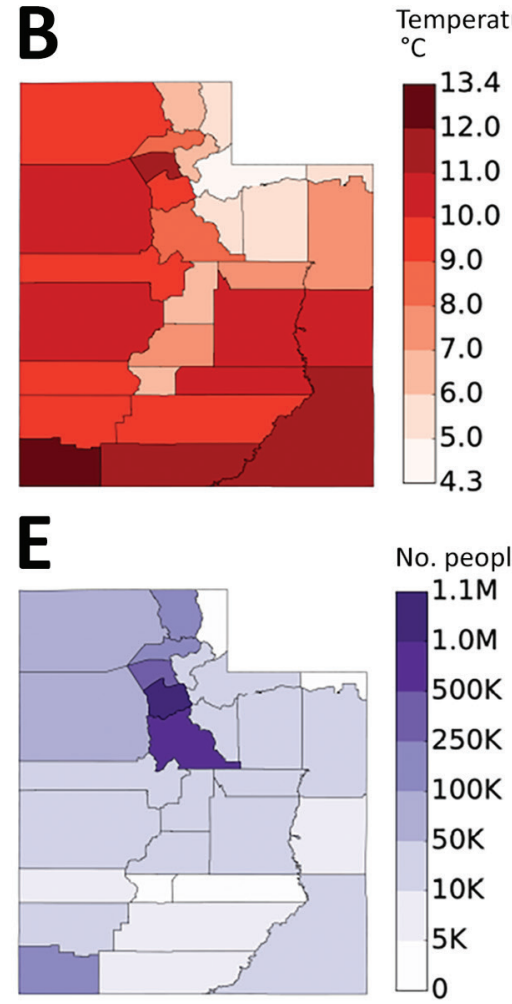

No. people

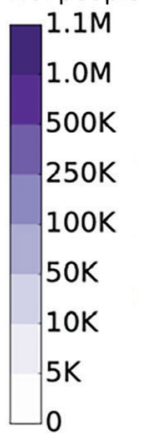

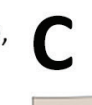

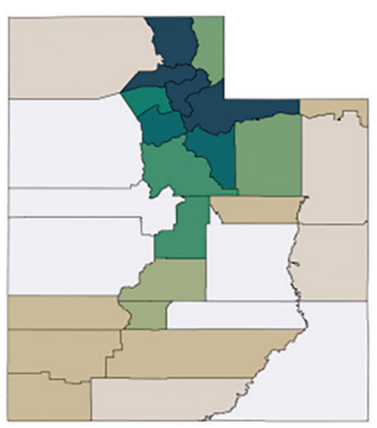

Precipitation. $\mathrm{mm}$

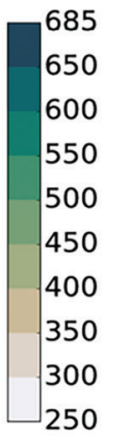

Figure 3. Comparison of mean coccidioidomycosis incidence (per 100,000 population per year) by county, Utah, 2009$2015(\mathrm{~A})$, with mean annual air temperature (B); precipitation, $\mathrm{mm}(\mathrm{C})$; construction permits per 100,000 population (D); and population $(E) . K$, thousand; $M$, million. 
Table 3. Distribution by county of coccidioidomycosis cases reported to the Utah Department of Health, Utah, USA, 2009-2015

\begin{tabular}{|c|c|c|c|c|}
\hline \multirow[b]{2}{*}{ County* } & \multirow[b]{2}{*}{ Total $(\%) \dagger$} & \multirow{2}{*}{$\begin{array}{c}\text { Observed mean } \\
\text { cases/year }\end{array}$} & \multicolumn{2}{|c|}{ Mean incidence/100,000 population/year } \\
\hline & & & Observed & Estimated \\
\hline Washington & $174(47.5)$ & 24.9 & 17.2 & 17.2 \\
\hline Salt Lake & $79(21.6)$ & 11.3 & 1.06 & -0.01 \\
\hline Davis & $23(6.3)$ & 3.29 & 1.02 & -0.11 \\
\hline Utah & $21(5.7)$ & 3.00 & 0.56 & 1.00 \\
\hline Iron & $17(4.6)$ & 2.43 & 5.23 & 4.18 \\
\hline Weber & $10(2.7)$ & 1.43 & 0.60 & -0.79 \\
\hline Tooele & $6(1.6)$ & 0.86 & 1.43 & 0.65 \\
\hline Summit & $5(1.4)$ & 0.71 & 1.93 & 4.57 \\
\hline Beaver & $4(1.1)$ & 0.57 & 8.83 & 6.93 \\
\hline Cache & $4(1.1)$ & 0.57 & 0.50 & 1.14 \\
\hline Garfield & $3(0.8)$ & 0.43 & 8.44 & 7.32 \\
\hline Box Elder & $2(0.5)$ & 0.29 & 0.85 & -0.03 \\
\hline Kane & $2(0.5)$ & 0.29 & 5.95 & 4.73 \\
\hline Juab & $2(0.5)$ & 0.29 & 2.78 & 0.64 \\
\hline Sanpete & $2(0.5)$ & 0.29 & 1.01 & 0.20 \\
\hline Uintah & $2(0.5)$ & 0.29 & 0.80 & 2.70 \\
\hline Carbon & $1(0.3)$ & 0.14 & 0.68 & -0.88 \\
\hline Daggett & $1(0.3)$ & 0.14 & 12.9 & 13.7 \\
\hline Duchesne & $1(0.3)$ & 0.14 & 0.71 & 2.62 \\
\hline Emery & $1(0.3)$ & 0.14 & 1.34 & -1.00 \\
\hline Morgan & $1(0.3)$ & 0.14 & 1.40 & 2.43 \\
\hline Rich & $1(0.3)$ & 0.14 & 6.33 & 11.0 \\
\hline Sevier & $1(0.3)$ & 0.14 & 0.69 & -0.98 \\
\hline Wasatch & $1(0.3)$ & 0.14 & 0.58 & 5.66 \\
\hline Utah & $366 \ddagger(100)$ & 52.3 & 1.83 & 3.45 \\
\hline
\end{tabular}

2018, which averages 4.3 million visitors/year (National Park Services Visitor Use Statistics, https:/ / irma.nps.gov/STATS).

Of additional interest, when climate, population, and construction factors were taken into account, our model predicted a second hotspot for future high coccidioidomycosis incidence in the northeastern corner of the state. Although the current observed incidence in these counties is low, they are also sparsely populated but with substantial population growth expected, the incidence in these areas might also be expected to increase. This finding was especially intriguing in the context of the 2001 coccidioidomycosis outbreak (adjusted mean incidence: 2.70 cases/100,000 population/year) that occurred in Uintah County in northeast Utah, which includes part of Dinosaur National Monument.

In addition to the factors that we included in our analyses, other environmental factors such as soil $\mathrm{pH}$ and composition and the geographic distribution of small mammal species important in the lifecycle of Coccidioides (24) might also contribute to the geographic variation in disease incidence and merit additional research. Future studies including PCR testing of soil and air samples will be important to clarify the interactions between the environment and Coccidioides pathogens and enable more accurate epidemiologic forecasting.
The observed all-cause mortality in the study cohort was higher than reported in an earlier study (25). Because roughly one third of cases in our study were diagnosed in a hospital, delay in diagnosis because of lack of clinical awareness might have led to increased death. In addition, because of this finding of elevated death rates, potential differences in virulence among Coccidioides strains circulating in Utah should be considered to better understand this phenomenon (26). Congruent with findings from prior studies (27), persons of non-White race and those taking immunosuppressive medications were more likely to have the nonpulmonary form of the disease.

Given the high incidence in southwestern Utah, more widespread efforts to educate clinicians about coccidioidomycosis are urgently needed, especially as the population increases and ages. In these areas, where pulmonary and infectious diseases specialists are scarce, primary care providers and those working in urgent care settings serve as the front line for diagnosing and treating diseases such as coccidioidomycosis. Because nearly one third of patients in this cohort were diagnosed as part of a workup for malignancy, our findings suggest that additional awareness efforts should be targeted to the hematologists and oncologists serving a broad referral area in Utah, Nevada, and Arizona. Radiologists should also be included so that they might 
consider coccidioidomycosis as a differential diagnosis in the presence of relevant radiological features.

An additional 115 patients living in southwestern Utah were excluded from the study although they had positive IgG ELISA results because of a lack of clinical disease evidence. It is unclear if these cases represent temporally remote or subclinical exposures with long-lasting seropositivity, questioning the current paradigm that Coccidioides IgG wanes over time. Additional analysis of that subgroup of the cohort will need to be conducted to further understand this phenomenon.

Our study's first limitation is that the reported demographic and clinical data are based on the subset of cases from Intermountain Healthcare identified within the state, but incidence data are based on cases reported to the state health department. When we manually compared Intermountain Healthcare patient-level data with statewide reportable disease data from UDOH for the same cases, there were differences, particularly for case confirmation and regional distribution (e.g., more reportable cases in northern counties). This might have been because of decreased specificity related to the granularity of laboratory-initiated health department data and decreased sensitivity in Intermountain Healthcare data, where not all possible cases might have been detected. For example, not all physicians used EMR, and in some cases clinical data were missing; therefore, we excluded those cases to maintain data integrity. This process likely led to an underestimation of the true number of cases within the state. Third, we used ZIP code information as a surrogate for the location of disease acquisition. Without a direct survey of patients to elucidate occupational and recreational exposures, this might skew the distribution of disease across the state. Last, we excluded cases from the demographic and clinical analyses when Coccidioides CF was positive at 1:2 titer, although UDOH includes cases with CF positive at that titer. However, manual review revealed only 2 cases excluded with an exact 1:2 titer without another positive serologic result. One case had missing clinical information that did not permit us to confirm symptomatology, and 1 case was imported from outside of the state.

In conclusion, we found that coccidioidomycosis incidence in Utah is higher than previously described and clusters primarily in the recognized endemic area in the southwestern part of the state. However, in geospatial modeling accounting for environmental factors, we identified a second potential area in the northeast that might have conditions conducive to future increases in Coccidioides incidence. Increasing the awareness of front-line providers and especially oncologists in southwestern Utah is necessary for early recognition and clinical management of the disease, but enhanced clinical surveillance in the northeast might increase case detection. Serologic and environmental testing might further elucidate distribution of Coccidioides organisms and determine the effects of air temperature, population growth, and construction on coccidioidomycosis disease burden in the state.

This submission is under public release with the approved LA-UR-20-21991. Institutional funding was provided by an Intermountain Research and Medical Foundation grant. M.E.G. had support provided by her laboratory-directed research and development director's postdoctoral fellowship and the Center for Nonlinear Studies at Los Alamos National Laboratory.

The findings and conclusions in this article are those of the authors and do not represent the official position of the Centers for Disease Control and Prevention or Los Alamos National Laboratory. Los Alamos National Laboratory, an affirmative action/equal opportunity employer, is managed by Triad National Security, LLC, for the National Nuclear Security Administration of the U.S. Department of Energy under contract 89233218CNA000001.

\section{About the Author}

Dr. Carey is an assistant professor in the Division of Infectious Diseases at the University of Utah School of Medicine in Salt Lake City. Her primary research interests include the epidemiology and clinical characteristics of coccidioidomycosis within the state.

\section{References}

1. Pappagianis D. Epidemiology of coccidioidomycosis. In: McGinnis M, editor. Current topics in medical mycology, vol. 2. New York City: Springer; 1988. p. 199-238.

2. Galgiani JN, Ampel NM, Blair JE, Catanzaro A, Geertsma F, Hoover SE, et al. 2016 Infectious Diseases Society of America (IDSA) clinical practice guideline for the treatment of coccidioidomycosis. Clin Infect Dis. 2016;63:e112-46. https://doi.org/10.1093/cid/ciw360

3. Edwards PQ, Palmer CE. Prevalence of sensitivity to coccidioidin, with special reference to specific and nonspecific reactions to coccidioidin and to histoplasmin. Dis Chest. 1957;31:35-60. https:/ / doi.org/10.1378/chest.31.1.35

4. Centers for Disease Control and Prevention (CDC). Increase in reported coccidioidomycosis - United States, 1998-2011. MMWR Morb Mortal Wkly Rep. 2013;62:217-21.

5. Centers for Disease Control and Prevention. Coccidioidomycosis in workers at an archeologic siteDinosaur National Monument, Utah, June-July 2001. JAMA. 2001;286:3072-3. https://doi.org/10.1001/jama.286.24.3072

6. Perera $\mathrm{P}$, Stone $\mathrm{S}$. Update on emerging infections: news from the Centers for Disease Control and Prevention Ann Emerg Med. 2002;39:566-9. 
7. Petersen LR, Marshall SL, Barton-Dickson C, Hajjeh RA, Lindsley MD, Warnock DW, et al. Coccidioidomycosis among workers at an archeological site, northeastern Utah. Emerg Infect Dis. 2004;10:637-42. https://doi.org/10.3201/ eid1004.030446

8. Gorris ME, Cat LA, Zender CS, Treseder KK, Randerson JT. Coccidioidomycosis dynamics in relation to climate in the southwestern United States. Geohealth. 2018;2:6-24. https:/ / doi.org/10.1002/2017GH000095

9. Webb BJFJ, Ferraro JP, Rea S, Kaufusi S, Goodman BE, Spalding J. Epidemiology and clinical features of invasive fungal infection in a US health care network. Open Forum Infect Dis. 2018;5:ofy187. https:// doi.org/10.1093/ofid/ ofy 187

10. De Pauw B, Walsh TJ, Donnelly JP, Stevens DA, Edwards JE, Calandra T, et al.; European Organization for Research and Treatment of Cancer/Invasive Fungal Infections Cooperative Group; National Institute of Allergy and Infectious Diseases Mycoses Study Group (EORTC/MSG) Consensus Group. Revised definitions of invasive fungal disease from the European Organization for Research and Treatment of Cancer/Invasive Fungal Infections Cooperative Group and the National Institute of Allergy and Infectious Diseases Mycoses Study Group (EORTC/MSG) Consensus Group. Clin Infect Dis. 2008;46:1813-21. https:/ / doi.org/ 10.1086/588660

11. Daly C, Halbleib M, Smith JI, Gibson WP, Doggett MK, Taylor GH, et al. Physiographically sensitive mapping of climatological temperature and precipitation across the conterminous United States. Int J Climatol. 2008;28:2031-64. https://doi.org/10.1002/joc.1688

12. Daly C, Neilson RP, Phillips DL. A statistical-topographic model for mapping climatological precipitation over mountainous terrain. J Appl Meteorol. 1994;33:140-58. https:/ / doi.org/10.1175/1520-0450(1994)033<0140:ASTMF $\mathrm{M}>2.0 . \mathrm{CO} ; 2$

13. Kolivras KN, Comrie AC. Modeling valley fever (coccidioidomycosis) incidence on the basis of climate conditions. Int J Biometeorol. 2003;47:87-101. https:/ / doi.org/ 10.1007/s00484-002-0155-x

14. Comrie AC. Climate factors influencing coccidioidomycosis seasonality and outbreaks. Environ Health Perspect. 2005;113:688-92. https://doi.org/10.1289/ehp.7786

15. Park BJ, Sigel K, Vaz V, Komatsu K, McRill C, Phelan M, et al. An epidemic of coccidioidomycosis in Arizona associated with climatic changes, 1998-2001. J Infect Dis. 2005;191:1981-7. https:// doi.org/10.1086/430092

16. Weaver EA, Kolivras KN. Investigating the relationship between climate and valley fever (coccidioidomycosis). EcoHealth. 2018;15:840-52. https://doi.org/10.1007/ s10393-018-1375-9

17. Cummings KC, McDowell A, Wheeler C, McNary J, Das R, Vugia DJ, et al. Point-source outbreak of coccidioidomycosis in construction workers. Epidemiol Infect. 2010;138:507-11. https:/ / doi.org/10.1017/S0950268809990999
18. Laws RL, Cooksey GS, Jain S, Wilken J, McNary J, Moreno E, et al. Coccidioidomycosis outbreak among workers constructing a solar power farm-Monterey County, California, 2016-2017. MMWR Morb Mortal Wkly Rep. 2018;67:931-4. https://doi.org/10.15585/mmwr.mm6733a4

19. Wilken JA, Sondermeyer G, Shusterman D, McNary J, Vugia DJ, McDowell A, et al. Coccidioidomycosis among workers constructing solar power farms, California, USA, 2011-2014. Emerg Infect Dis. 2015;21:1997-2005. https:/ / doi.org/10.3201/eid2111.150129

20. Arizona Department of Health Services, Office of Infectious Disease Services. Rates of reported cases of notifiable diseases by year for Arizona, 2005-2015, per 100,000 population [cited 2019 Jun 19]. https:/ / www.azdhs.gov/ documents/preparedness/epidemiology-disease-control/ disease-data-statistics-reports/data-statistics-archive/ t3a1-rates.pdf

21. California Department of Public Health, Division of Communicable Diseases Control, Infectious Diseases Branch, Surveillance and Statistics Section. Yearly summaries of selected general communicable diseases in California, 2001-2010 [cited 2019 Jun 19]. https:/ / www.cdph.ca.gov/ Programs/CID/DCDC/CDPH\%20Document\%20Library/ YearlySummaryReportsofSelectedGenCommDiseasesinCA 2001-2010.pdf

22. California Department of Public Health, Division of Communicable Diseases Control, Infectious Diseases Branch, Surveillance and Statistics Section. Epidemiologic summary of coccidioidomycosis in California, 2016 [cited 2019 Jun 19]. https://www.cdph.ca.gov/Programs/CID/DCDC/CDPH\%20 Document\%20Library/CocciEpiSummary2016.pdf

23. Brown J, Benedict K, Park BJ, Thompson GR III. Coccidioidomycosis: epidemiology. Clin Epidemiol. 2013; 5:185-97.

24. Taylor JW, Barker BM. The endozoan, small-mammal reservoir hypothesis and the life cycle of Coccidioides species. Med Mycol. 2019;57(Supplement_1):S16-20. https:// doi.org/10.1093/mmy/myy039

25. Huang JY, Bristow B, Shafir S, Sorvillo F. Coccidioidomycosisassociated Deaths, United States, 1990-2008. Emerg Infect Dis. 2012;18:1723-8. https://doi.org/10.3201/eid1811.120752

26. Barker BM, Jewell KA, Kroken S, Orbach MJ. The population biology of coccidioides: epidemiologic implications for disease outbreaks. Ann N Y Acad Sci. 2007;1111:147-63. https://doi.org/10.1196/annals.1406.040

27. Odio CD, Marciano BE, Galgiani JN, Holland SM. Risk factors for disseminated coccidioidomycosis, United States. Emerg Infect Dis. 2017;23:308-11. https:/ / doi.org/10.3201/ eid2302.160505

Address for correspondence: Adrienne Carey, Division of Infectious Diseases, University of Utah School of Medicine, $30 \mathrm{~N}$ 1900 E, Rm 4B319, Salt Lake City, UT 84132, USA; email: adrienne. carey@hsc.utah.edu 